\title{
Adsorptive Removal of Manganese from Manganese Slag Aqueous Solutions Using Biochars Loaded with Organic Acid-Fe
}

\author{
Zu-Yong CHEN ${ }^{1, a}$, Fang LIU ${ }^{1, b^{*}}$, Yuan-Sheng LIU ${ }^{2, c}$, Tong-Da BU ${ }^{2, d}$, \\ Jian $\mathrm{ZHU}^{1, \mathrm{e}}$ \\ ${ }^{1}$ College of Resources and Environmental Engineering, Guizhou University, Guiyang 550025, China \\ ${ }^{2}$ College of Agriculture of Guizhou University, Guiyang 550025, China \\ aqingfeng340@126.com, ${ }^{\mathrm{b}}$ Ifang6435 @163.com, corresponding author, ${ }^{\mathrm{c}, \mathrm{d}, \mathrm{e}}$ lysheng88@163.com \\ ${ }^{*}$ Corresponding author
}

Keywords: Biochar Modification, Organic Acid-Fe, Manganese, Adsorptive Removal, Slag.

\begin{abstract}
Manganese adsorptive removal is an important treatment process in constructed wetlands to deal with considerable amounts of tailing wastewater, many materials have been proposed for its removal. This work is aimed to examining the potential of biochars sorbent materials for removing Mn ions from manganese slag aqueous solutions by modified biochars. The biochars with different organic acid-Fe ratios were prepared; factors on $\mathrm{Mn}$ adsorption including mixing ratio, Fe adsorption rate, and the BET surface of the modified biochars were discussed and the sorption efficiency of $\mathrm{Mn}$ was investigated through column adsorption experiments. According to our study, it's clearly that loaded organic acid biochar with greater Fe content removed higher percent of $\mathrm{Mn}$ from the aqueous solution. Contents of $\mathrm{Fe}_{2} \mathrm{O}_{3}(30-103 \%), \mathrm{Fe}_{3} \mathrm{O}_{4}(65-106 \%)$ and $\mathrm{CaCO}_{3}(4-80 \%)$ increased after loaded with organic acid-Fe in the biochars. With the increasing Fe content $(2.58-5.07 \%)$ in biochar, the BET surface area of the Citric Acid-Fe biochar composites decreased from $81 \mathrm{~m}^{2} / \mathrm{g}$ to $35 \mathrm{~m}^{2} / \mathrm{g}$, while the EDTA-Fe biochar composites decreased from $96 \mathrm{~m}^{2} / \mathrm{g}$ to $22 \mathrm{~m}^{2} / \mathrm{g}$. The fixed loaded Fe biochars mixtures had a reduction of $4.02 \%$ to $32.01 \%$ in Mn sorption contrasting with raw biochar. The modified biochars could be used to remove the Mn ions in the tailing wastewater.
\end{abstract}

\section{Introduction}

The world rapidly growing demand for manganese has made it increasingly important to develop processes for economic recovery of manganese from low grade manganese ores and other secondary sources [1]. In recent years, the world manganese demand has been driven by soaring steel production, particularly in China. These manganese-containing industrial waste effluents could be potentially important manganese sources [2]. Several acid leaching processes have been developed to recover manganese from these kinds of manganese minerals. Das et al. [3] investigated the recovery of manganese from ferro-manganese slag by acid leaching. The slag from ferro-manganese manufacture contained $12-30 \% \mathrm{Mn}$ (II) with the main impurities being $\mathrm{CaO}, \mathrm{SiO}_{2}$, and $\mathrm{Al}_{2} \mathrm{O}_{3}$.

The use of biochar is on the draft agenda for the international climate change negotiations in Copenhagen in December 2015. Biochar is exceptionally stable and can be stored underground for hundreds of years without releasing its carbon into the atmosphere and it improves the fertility of the soil [4]. These effects are the result of biochar's structure, which is full of microscopic pores that can harbor useful bacteria and fungi [5]. Turning vast amounts of biomass crop wastes and other biomass into charcoal and spreading it on soils can sequester carbon and boost crop productivity [6]. Recently, biochar has been used frequently as a suitable biosorbent to remove toxic metals from wastewater [7, 8]. This improvement of suitable biochars has been studied in numerous, very recent studies Trakal et al. [8], Mohan et al. [9], Wang et al. [10], Inyang et al. [11], where enhancement of metal sorption has been experimentally confirmed. Despite these novel studies, there is still missing information about the metal sorption mechanisms after the magnetization process. Considering this lack of knowledge, the biochar samples presented in the previous paper [6] were magnetically modified and subjected to identical geochemical and spectroscopic investigations. 
The primary aim of this investigation was to develop a Fe-contained and organic acid magnetic biochar for the recovery of manganese from aqueous solution. For this purpose, locally available harvest trash biomass of agricultural crop was pyrolyzed at $600^{\circ} \mathrm{C}$ after being impregnated with ferrous chloride and organic acid solution. The performance and adsorption mechanism for ferrous recovery from water solution, and subsequently the efficiency of organic acid - sorbed biochar as a fertilizer were examined. Leaching behavior of ferro-manganese slag was also investigated in simulating experiments. In order to realize the effect of biochar on manganese slag water contamination, and provides the theory basis of metal mobility of manganese slag for pollution control.

\section{Materials and Methods}

\section{Materials Collection and Preparation}

Exactly the same waste agro-materials as in previous study [6] were used for the biochar preparation in this study. The source of raw materials of biochar was straw of agricultural crop, and it was pyrolyzed at $600^{\circ} \mathrm{C}$ in a muffle furnace at atmospheric pressure with a retention time of $30 \mathrm{~min}$. The pyrolyzed products were cooled, and the resulting biochars were ground, homogenized, sieved $(1 \mathrm{~mm})$, washed with ultra-clean water (Merck Millipore D $24 \mathrm{UV}$, USA), and dried at $60^{\circ} \mathrm{C}$ for $24 \mathrm{~h}$ until constant weight, and finally stored in polystyrene valve bag for later use. The electrolytic manganese slag were collected in Zhenyuan county of Guizhou province in China, all the collect samples of electrolytic manganese slag were compound samples of topsoil. The samples were grinded and sifted through $1 \mathrm{~mm}$ nylon sieve after natural air drying, and then loaded into polystyrene valve bag for later use.

The citric acid and the ethylene diamine tetraacetic acid (EDTA) were used as typical organic acid to load with Fe in this study. During this process, biochars (preparation above) were putted into the two organic acids respectively in the setting density $0.2-0.6 \mathrm{~mol} / \mathrm{L}$, and there were the same amounts of Fe(III) molarity in the aqueous solution contrast with organic acids. Then, the suspensions of all organic acids experiments were shaken at $250 \mathrm{rpm}$ using an end-over-end agitator for $24 \mathrm{~h}$, filtered through $1 \mathrm{~mm}$ nylon filter, washed with ultra-clean water and dried at $60^{\circ} \mathrm{C}$ for $12 \mathrm{~h}$ until constant weight, and finally stored in polystyrene valve bag for further use.

\section{Column Adsorption Experiments}

Equipment: All column leaching tests have been conducted under laboratory conditions $\left(20^{\circ} \mathrm{C}\right) \mathrm{using}$ PVC columns with an internal diameter of $7.5 \mathrm{~cm}$ and a length of $50 \mathrm{~cm}$. The electrolytic manganese slags (preparation in section 2.1) were homogenized with the joined biochars (loaded with organic acid-Fe) in a series of fixed ratio $(0 \%, 5 \%, 10 \%$, and $15 \%)$. Packing of homogenized manganese slags took place in 15-20 increments, and each increment was packed slightly before the next one was placed on top until the column was completely filled with $4 \mathrm{~kg}$ manganese slags. After manganese slags were filled uniformly, a filter paper must be laid on the top of the slags. Make sure the filter paper was level, so the liquid drip onto the filter paper was uniformly distributed on the surface of manganese slags. Leaching solution was horizontally placed in a high position as far as possible; to make hydraulic change minimize during a leaching time.

Procedure: The leaching solution was ultra-clean water. The experiments were performed twice for all treatments. Continuously leaching manganese slags for $24 \mathrm{~h}$ with the leaching solution were taken up to simulate the light rain $\left(13 \mathrm{~mm} \cdot 24 \mathrm{~h}^{-1}\right)$ leaching on the manganese slags. Prior to detection, samples were filtrated to a $50 \mathrm{ml}$ plastic centrifuge tube with a $0.45 \mu \mathrm{m}$ filter membrane. The remaining collected liquid solution in the collector must be poured away out entirely. The next leaching was carried every three days, and the whole leaching experiment last for 15 days.

Each collected water sample was acidified with pure $\mathrm{HNO}_{3}$ to adjust its $\mathrm{pH}$ value to below 2 to avoid Mn hydroxide precipitation within $24 \mathrm{~h}$ after sample was taken. All the samples were stored at $4{ }^{\circ} \mathrm{C}$ in the refrigerator before determination.

\section{Analytical Methods}

To test the $\mathrm{Fe}$ (III) loading on iron oxide/activated carbon composite adsorbent, about $0.5 \mathrm{~g}$ of 
composite adsorbent was ashed at $600^{\circ} \mathrm{C}$ and then digested with $25 \mathrm{~mL}$ of concentrated hydrochloric acid. The fraction of dissolved heavy metals was attained by analyzing the content of filtered samples. The major elements ( $\mathrm{Fe}$ and $\mathrm{Mn}$ ) in dissolved solutions and digestion solutions were determined with Atomic Absorption Spectrophotometer (AAS ZEEnit-700P, Germany) unit with flame atomization, specific surface area determined using the BET multilayer adsorption isotherm (Micromeritics ASAP 2000, USA), and the precipitated phases detected using X-ray diffraction analyses (LabX XRD-6000, Japan). Blanks and appropriate certified standard reference materials were analyzed as unknowns with every batch of samples. All the related glassware were soaked in $20 \% \mathrm{HNO}_{3}$ for 24 hours and then thoroughly rinsed with the deionized water before being used.

The analysis of statistical data was conducted by using the Statistical Product and Service Solutions (SPSS 22). The entire graphs were drawn by MDI Jade 6.5 or Origin Pro 9.1.

\section{Results and Discussion}

\section{Characteristics of Studied Biochars}

XRD analysis was carried out for the composite adsorbent and the pure iron oxide, the analysis results are shown in Fig.1. The XRD analysis revealed that raw biochar without organic acid-Fe addition is dominated with abroad diffraction peak at two theta around $26^{\circ}$. Compared with that of raw biochar, the prepared

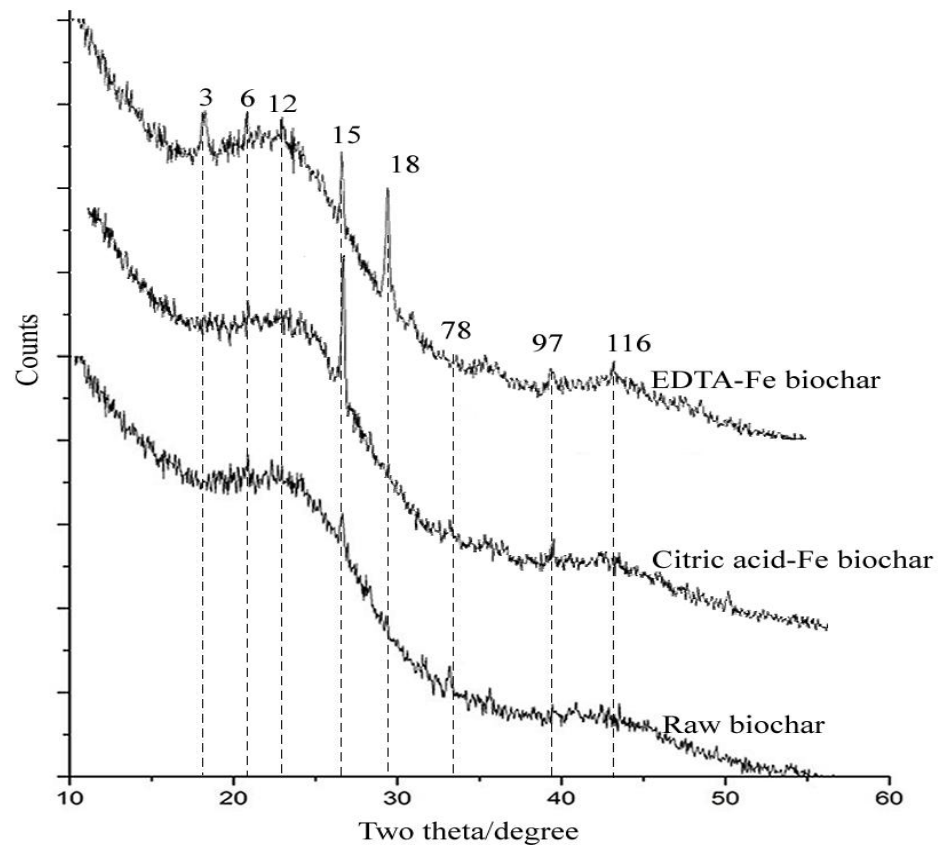

Fig.1 XRD patterns of studied biochar samples before and after modification.

Organic acid-Fe biochars composites showed typical hydrotalcite compound structure with sharp reflection peaks including "12", "15", "97", as well as "6", "116". It was evident from Figure 1 that the contents of $\mathrm{Fe}_{2} \mathrm{O}_{3}, \mathrm{Fe}_{3} \mathrm{O}_{4}$ and $\mathrm{CaCO}_{3}$ increased before and after loaded with organic acid-Fe in the range of $26-30^{\circ}$. The three of them increased by $30 \%, 106 \%$ and $4 \%$, respectively, after loaded with Citric Acid-Fe, while increased by $103 \%, 65 \%$ and $80 \%$, respectively, after loaded with EDTA-Fe. Loaded with EDTA-Fe was a more effective than loaded with Citric Acid-Fe in modifing biochars characteristics. XRD analyses of the pure iron oxide suggest the presence of a cubic iron oxide phase, which may be related to the presence of maghemite $\left(\gamma-\mathrm{Fe}_{2} \mathrm{O}_{3}\right)$, goethite $(\alpha-\mathrm{FeO}(\mathrm{OH}))$, hematite $\left(\alpha-\mathrm{Fe}_{2} \mathrm{O}_{3}\right)$ and magnetite $\left(\mathrm{Fe}_{3} \mathrm{O}_{4}\right)$, so the prepared iron oxides are magnetic. For the composite, these peaks appear broader, suggesting a smaller crystallite size. In summary, the improvement of metal sorption by magnetic modification was related to the origin of the material, with the well-structured biochars more available for modification $[6,8]$. 


\section{Ferric Iron Loading Efficiency}

The Fe content and textural properties of the prepared samples are showed in Fig.2. With concentration of Fe increasing from 0.2 to $0.6 \mathrm{~mol} / \mathrm{L}$ (Fig.2a), the loaded icon Fe content increased from $2.58 \%$ to $4.73 \%$ in citric acid solution, when the loaded icon Fe content increased from $3.45 \%$ to $5.07 \%$ in EDTA solution. As previously described, after the $\mathrm{Fe}$ introduction there were lots of $\mathrm{Fe}_{2} \mathrm{O}_{3}$ in biochar samples after loaded with organic acid-Fe. The specific formation of $\mathrm{Fe}_{2} \mathrm{O}_{3}$ was likely through the reaction sequence of $\mathrm{FeCl}_{3} \rightarrow \mathrm{Fe}(\mathrm{OH})_{3} \rightarrow \mathrm{FeO}(\mathrm{OH}) \rightarrow 2 \mathrm{Fe}_{3} \mathrm{O}_{4}$ with gases $\mathrm{HCl}, \mathrm{H}_{2} \mathrm{O}$, and $\mathrm{CO}_{2}$ released from the respective reactions [12]. Similar results were also observed during carbonizing the ferric chloride soaked sawdust [13], ferric and ferrous chloride impregnated orange peel powder [14]. The adsorption will be enhanced by the goethite-organic acid compound colloid which from the organic acid and goethite interaction. For this reason, $0.6 \mathrm{~mol} / \mathrm{L}$ samples were selected for subsequent evaluation.
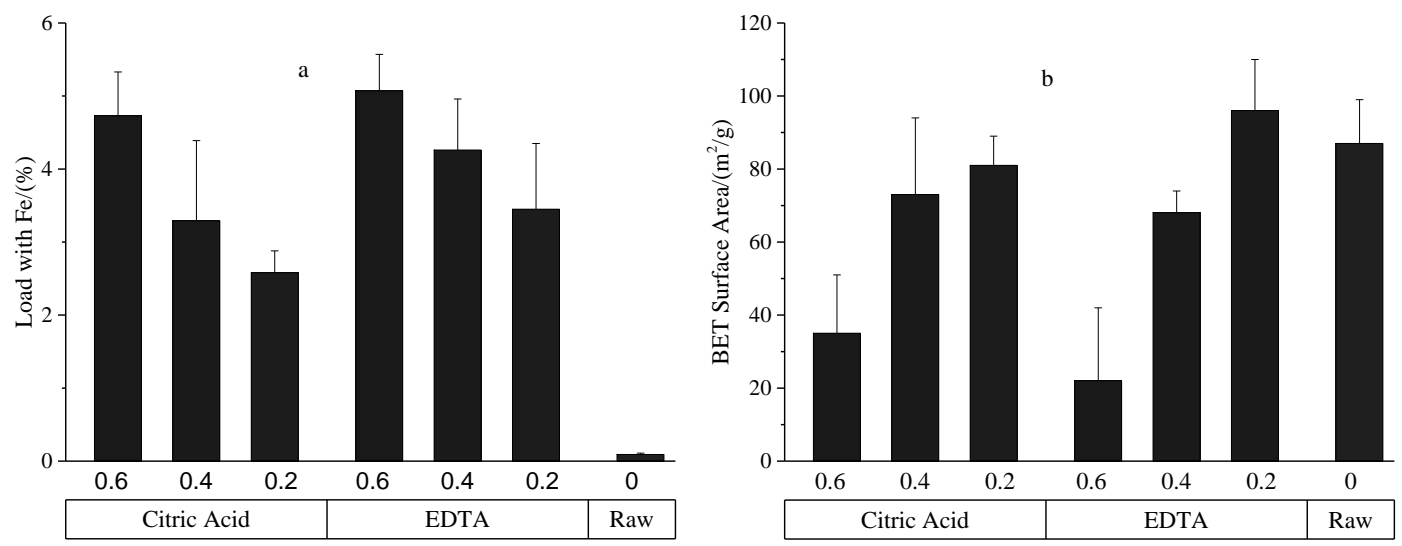

Fig.2 Properties of the studied biochars before and after loaded Fe modification

Compared with raw biochar (Fig.2b), after the Fe introduction the BET surface area in the two biochar samples decreased after loaded with organic acid-Fe introduction. With the increasing $\mathrm{Fe}$ content $(0.2 \rightarrow 0.6 \mathrm{~mol} / \mathrm{L})$, the BET surface area of the Citric Acid-Fe biochar composites decreased from $81 \mathrm{~m}^{2} / \mathrm{g}$ to $35 \mathrm{~m}^{2} / \mathrm{g}$, while the BET surface area of the EDTA-Fe biochar composites decreased from $96 \mathrm{~m}^{2} / \mathrm{g}$ to 22 $\mathrm{m}^{2} / \mathrm{g}$ also proved these results. The BET surface area decreased after modification of the two pristine biochars with high specific surface area, whereas it increased for those biochars with low surface area. This could be explained by the fact that with the metal salt content continuously increasing, some larger pore was probably produced or the surface of the biochar was possibly covered by the metal oxides formation during the salts dehydration process, resulted the BET surface area decrease[12, 15]. There were some previously studies described that with the increasing icon content(e.g. Fe, $\mathrm{Mg}$ ), the total pore volume(TPV) and the average pore radius(APR) of the biochar samples increased proved these reasons.

\section{Mn Sorption Efficiency}

Compared with controlled experiment (CK), which were pure manganese slags presented in this study, the fixed biochars mixtures had significantly lower solute of $\mathrm{Mn}$ in all cases (decrease of 3.21 to 46.29\%), and the higher sorption of Mn was in EDTA-Fe biochar (Fig.3). This improvement of the metal sorption efficiency can be explained by the presence of Fe oxides in the structure of the biochars, in agreement with the studies of Trakal et al. [8], Mohan et al. [9], Han et al. [16]. The sorption efficiency of raw biochars was changed minimally, and in the case of EDTA-Fe biochar, the efficiency was actually increased after the loaded Fe modification (46.29\%). But the non-loaded Fe biochar had a non-significant effect on $\mathrm{Mn}$ sorption by raw biochars. On the other hand, loaded Fe modification had a significant effect on Mn sorption in all the modified biochars. Compared with the non-loaded Fe biochar (raw biochar), the fixed loaded Fe biochars mixtures had a reduction of $4.02 \%$ to $32.01 \%$ contrasting with raw biochar. But in addition there were no significant effect on $\mathrm{Mn}$ sorption in the same biochar with different fix ratio (5-15\%). Nonetheless, our study clearly indicated that loaded organic acid biochar with greater Fe content removed higher percent of $\mathrm{Mn}$ from the solution. 


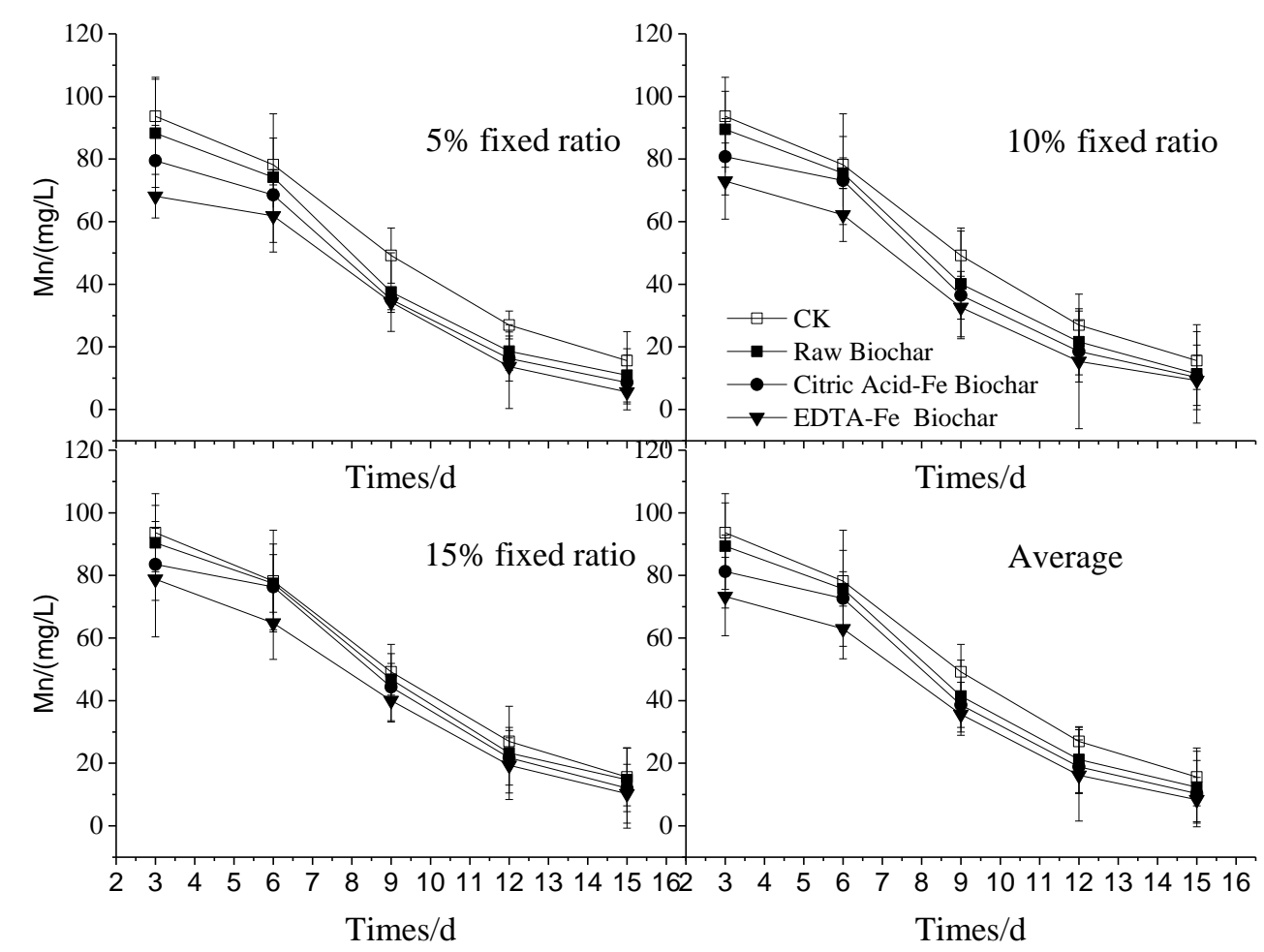

Fig.3 Time-dependent patterns of concentration curves of Mn in elution leachates from manganese slags.

\section{Conclusions}

The study clearly indicated that loaded organic acid biochar with greater Fe content removed higher percent of Mn from the aqueous solution. Impregnation with magnetite/maghemite greatly improved the sorption of $\mathrm{Mn}$, cation release was improved significantly after $\mathrm{Fe}$ oxide impregnation into the biochar structure. Contents of $\mathrm{Fe}_{2} \mathrm{O}_{3}(30-103 \%), \mathrm{Fe}_{3} \mathrm{O}_{4}$ (65-106\%)and $\mathrm{CaCO}_{3}$ (4-80\%)increased after loaded with organic acid-Fe in the biochars. With the increasing Fe content (2.58-5.07\%) in biochar, the BET surface area of the Citric Acid-Fe biochar composites decreased from $81 \mathrm{~m}^{2} / \mathrm{g}$ to $35 \mathrm{~m}^{2} / \mathrm{g}$, while the EDTA-Fe biochar composites decreased from $96 \mathrm{~m}^{2} / \mathrm{g}$ to $22 \mathrm{~m}^{2} / \mathrm{g}$. The fixed loaded Fe biochars mixtures had a reduction of $4.02 \%$ to $32.01 \%$ in Mn sorption contrasting with raw biochar.

\section{Acknowledgements}

This project was sponsored by The Innovative Talent Team Construction Project for Science and Technology of Guizhou Province (Project Number [2013]4020).

\section{References}

[1] Wensheng Z. and Chuyong C.. Manganese metallurgy review. Part I: Leaching of ores/secondary materials and recovery of electrolytic/chemical manganese dioxide. Hydrometallurgy, 3(4), 137-59(2007).

[2] Wensheng Z. and Chuyong C.. Manganese metallurgy, recovery and control - a literature review. Part I: Manganese Metallurgy CSIRO Minerals, Australia, DMR, 2803- 2809(2006).

[3] Das, S.C., Sahoo, P.K., Rao, P.K.. Technical note on recovery of manganese from low manganese content ferromanganese slag. Proceedings - Australasian Institute of Mining and Metallurgy, 272, 25-27(1979).

[4] Tan, X., Liu, Y., Zeng, G., Wang, X., Hu, X., Gu, Y., Yang, Z.. Application of biochar for the removal of pollutants from aqueous solutions. Chemosphere, 125, 70-85(2015). 
[5] Jeong, C., Dodla, S.K., Wang, J.J.. Fundamental and molecular composition characteristics of biochars produced from sugarcane and rice crop residues and their by-products. Chemosphere, 142, 4-13(2016).

[6] Trakal, L., Bingöl, D., Pohor `ely ', M., Hruška, M., Komárek, M.. Geochemical and spectroscopic investigations of $\mathrm{Cd}$ and $\mathrm{Pb}$ sorption mechanisms on contrasting biochars: engineering implications. Bioresour. Technol, 171, 442-451(2014).

[7] Yan, L., Kong, L., Qu, Z., Li, L., Shen, G.. Magnetic biochar decorated with ZnS nanocrytals for $\mathrm{Pb}$ (II) removal. ACS Sustainable Chem. Eng. 3, 125-132(2015).

[8] Trakal, Lukáš, Veselská, Veronika, Šafařík, Ivo, Vítková, Martina, and Č́íhalová, Sylva, et al.. Lead and cadmium sorption mechanisms on magnetically modified biochars. Bioresource Technology, 1, 318-324(2016).

[9] Mohan, D., Kumar, H., Sarswat, A., Alexandre-Franco, M., Pittman Jr., C.U.. Cadmium and lead remediation using magnetic oak wood and oak bark fast pyrolysis bio-chars. Chem. Eng. J. 236, 513-528(2014).

[10]Wang, S., Gao, B., Zimmerman, A.R., Li, Y., Ma, L., Harris, W.G., Migliaccio, K.W.. Removal of arsenic by magnetic biochar prepared from pinewood and natural hematite. Bioresour. Technol. 175, 391-395(2015).

[11]Inyang, M., Gao, B., Zimmerman, A., Zhou, Y., Cao, X.. Sorption and cosorption of lead and sulfapyridine on carbon nanotube-modified biochars. Environ. Sci. Pollut. Res, 22, 1868-1876(2015).

[12]Ronghua L., Jim J. W., Baoyue Z., Mukesh K. A., Amjad A., Zengqiang Z., Altaf Hussain L., et al.. Recovery of phosphate from aqueous solution by magnesium oxide decorated magnetic biochar and its potential as phosphate-based fertilizer substitute.Bioresource Technology, 215, 209-214(2016).

[13]Liu W.J., Tian K., Jiang H., Yu H.Q.. Facile synthesis of highly efficient and recyclable magnetic solid acid from biomass waste. Sci. Rep. 3, 2419-2423(2013).

[14]Baoliang C., Zaiming C., Shaofang L.. A novel magnetic biochar efficiently sorbs organic pollutants and phosphate. Bioresour. Technol, 102, 716-723(2011).

[15]Yao, Y., Gao, B., Chen, J.J., Zhang, M., Inyang, M., Li, Y.C., Alva, A., Yang, L.Y.. Engineered carbon (biochar) prepared by direct pyrolysis of $\mathrm{Mg}$-accumulated tomato tissues: characterization and phosphate removal potential. Bioresour. Technol, 138, 8-13(2013).

[16]Han, Z., Sani, B., Mrozik, W., Obst, M., Beckingham, B., Karapanagioti, H.K., Werner, D.. Magnetite impregnation effects on the sorbent properties of activated carbons and biochars. Water Res, 70, 394-403(2015). 